\title{
The Modeling of Funicular Structure Stability of Cordoba Mosque in Spain
}

\author{
Agung Sedayu \\ Faculty of Science and Technology Maulana Malik Ibrahim State Islamic University of Malang \\ E-mail:uinsedayu@gmail.com
}

\begin{abstract}
The Cordoba Mosque Spain is proof of the glory of Islam in the field of architecture and building construction. This mosque is supported by thousands of funicular that support reliable structural stability and construction. The arrangement of natural stone that complements the arch with a simple system that can make this mosque survive until now. This research is to find out the funicular structure of the Spanish Cordoba Mosque. The method is a structural modeling assisted by SAP 2000 non linear structure analysis program. The results showed that the weight of the stone that formed the curve made it work in place. Beside that, the level of stone curvature durability has supported the durability of the building structure material. Configuration and funicular dimensions also support the rigidity against horizontal, vertical and moment loads. Funiculars with each other connect and encourage building effects produce prestress in the all mosque building.
\end{abstract}

Keywords: Cordoba, Funicular, Mosque Modeling, Stability, Structure

\section{INTRODUCTION}

The Cordoba Mosque of Andalusian Spain was built by the Umayyad Caliph named Abdurahman III in 786 AD. The mosque was supported by around 1293 pairs of marble which comprise the funicular structure, columns, and walls of the mosque building. The other construction materials are timber that supports the roof of the mosque building. This mosque has the size of the building area is $180 \times 135 \mathrm{~m}$ with the average height of the mosque building is around $20 \mathrm{~m}$. Now this mosque is converted into a cathedral with all religious activities in it. A Cordoba Mosque is a historic site that leaves memories of the triumph of Islam in the fields of architecture and building technology. The Cordoba Mosque, now called La Mezquita-Catedral or Cordoba Mosque Cathedral is on the edge of al-Wadi al-Kabir river or also called the Rio Guadalquifir River (Sanjaya,2012:9). View of Cordoba mosque from the side of the Rio Guadalquifir river is shown in Figure 1.

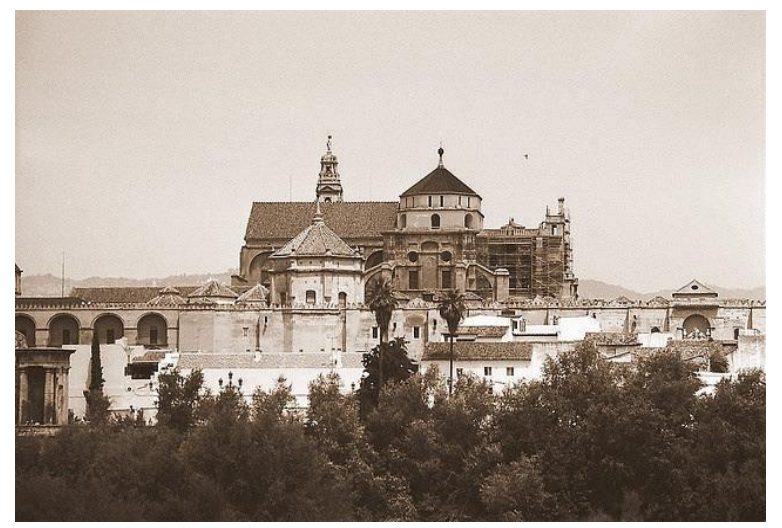

Figure 1. View of Cordoba Mosque from the Rio Guadalquifir River (source: Sanjaya, 2012).
The mosque has a uniqueness and excellence on all building elements, particularly the funicular structure which supports the stability of the overall building structure. This funicular structure is composed of marble stones that are processed in providing a high artistic and aesthetic art. This study aims to make a stability modeling of the funicular structure of the Cordoba mosque.

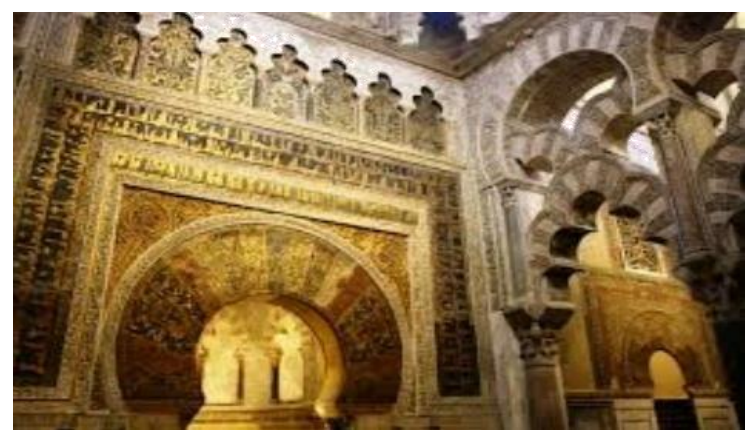

Figure 2. Ornaments that decorate the walls and columns of the mosque.

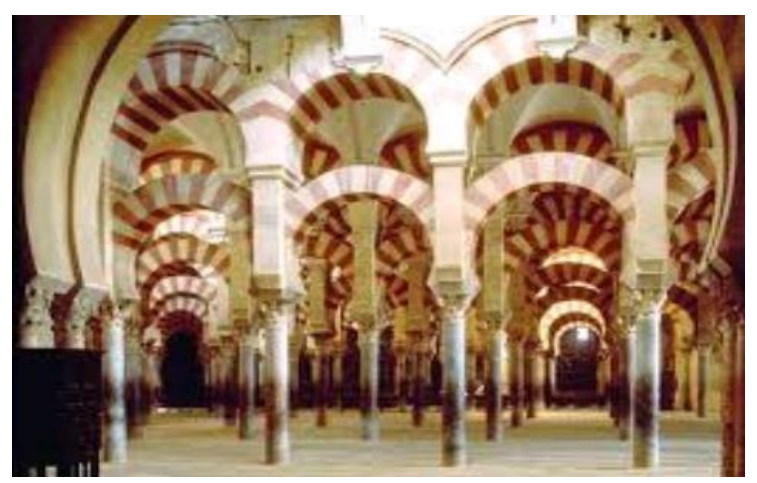

Figure 3. An arrangement of funicular structures supporting building stability. 


\section{MATERIALS AND METHOD}

The research method used is modeling with software analysis and engineering of the SAP 2000 nonlinear structure. The program of SAP 2000 nonlinear is one of the finite element-based computer programs with facilities of Graphic User Interface (GUI) that can be used to draw the structure model with analysis tools and check of structure design (Pramono, 2007). This program is very well known to scientists, academics, researchers, and practitioners of structure and construction of buildings. Before modeling is done, it must to study the object from previous studies and literature. The following are some of the previous studies that were used as comparative studies and references that will be used in this study. Arce (2006) conducted a study of Umayyad Arches, Vaults \& Domes: Merging and Re-creation, and its Contributions to Early Islamic Construction History. The process of merging western and eastern architectural models, building techniques and materials, carried out during the Umayyad period allowed the creation of a new expression of architectural and urban tradition required by the new power, that was to liberate Islamic material culture from antiquity. This process provided a new formal and technical catalogue for a new emerging culture and guaranteed the survival of "antique" cultural practices and elements, from both eastern and western traditions that otherwise would have been lost. This balance between continuity and change can be recognised particularly in the case of the city and the "urban culture" that was preserved thanks to the transformation process operated on it, that far from neglecting the "classical city" meant its preservation and revival. Fuentes and Huerta (2010) conducted research on Islamic domes of crossed-arches: Origin, geometry and structural behavior. This has generated a debate on their possible origin; a historical outline is given and the different hypotheses are discussed. Geometry is a fundamental part and the different patterns are examined. Though geometry has been thoroughly studied in Hispanic-Muslim decoration, the geometry of domes has very rarely been considered. The geometrical patterns in plan will be examined and afterwards, the geometric problems of passing from the plan to the three-dimensional space will be considered. Finally, a discussion about the possible structural behaviour of these domes is sketched. Hildebrand (2012) conducted research on Architectural Origins of the Mosque of Cordoba. The findings of that research has led to the conclusion that the Mosque of Cordoba's building structure is Pre-Islamic and should be reviewed to find out more about who built the original structure, how they did it, and for what purpose was it built. Sedayu (2013) attempted to compare three methods consisting of Cullmann diagram, Henneberg analytical, and computer program analysis of SAP 2000 structures. The results show that Cullmann diagrams can analyze simple truss, whereas Henneberg and SAP 2000 analytical methods can be used to analyze complex truss that cannot be solved by Cullmann diagram. Sedayu (2018) conducted a research on The priority of maintaining the reliability of sustainable construction at the ampel mosque Surabaya. The research resulted the highest research variables at the level of requirement is the ease and affordability in the maintenance of building construction components. Sedayu and Mangkoedihardjo (2018) also conducted a research about Performance evaluation of housing contractors by applying the principles of environmentally friendly infrastructure. The research variables are Assurance, Responsibility and Reliability, Performance, Aesthetics, Easiness, Durability, Architectural Design, and Environmentally Friendly.

\section{RESULTS AND DISCUSSION}

The structure model that studied is the main funicular that supports the construction of the Cordoba mosque as shown in Figure 4. The funicular structure is in the main area of the mosque. The dimensions of the funicular structure with a distance between columns equal to $3 \mathrm{~m}$, with the specification height $=3 \mathrm{~m}$ and diameter $=3 \mathrm{~m}$ (radius $=1.5 \mathrm{~m})$.

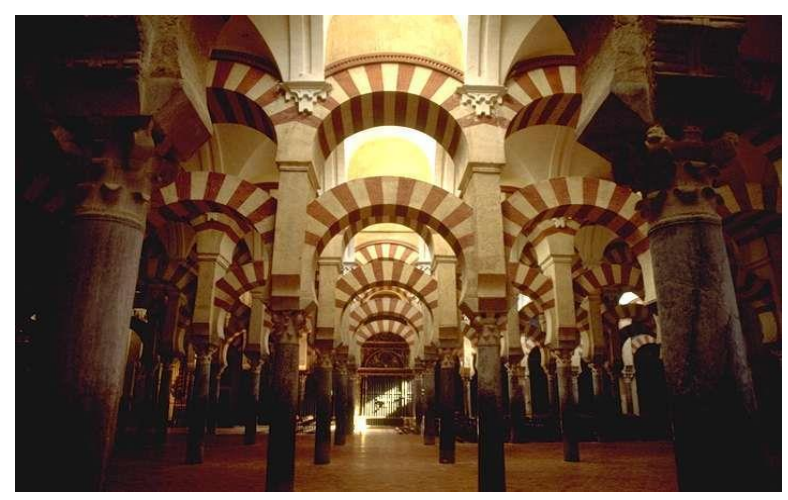

Figure 4. The funicular structure in the main room of the Cordoba Mosque building.

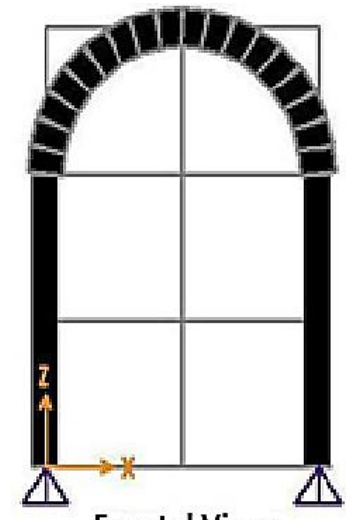

Frontal View

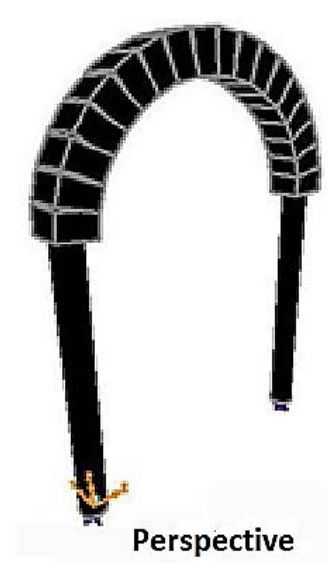

Perspective
Figure 5. Funicular model with stacked stones arrangement. 
The funicular structure at the Cordoba mosque consists of a pair of stacked stones with a simple joint, and between one funicular and the other support the strength of each other. The funicular structure used is the arc type. The funicular structure which also called structural curvature (curve) and the arc (Arc) The funicular is a structure formed from stem arch between two joints which consists of a vertical component (column) with a horizontal component (beam) into a single entity without being able to distinguish between them (Sedayu, 2013). The type of arches at the Cordoba mosque include three hinges arches with the many joints that are supported by arches stones. The basic model of arches structure in Cordoba mosque is described in Figure 5.

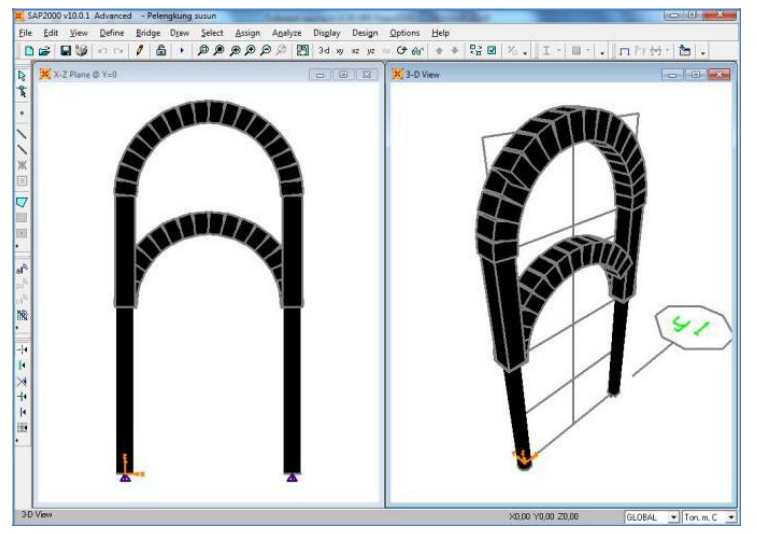

Figure 6. Two-level arches.

The Cordoba mosque that applies ancient arches with stone pieces. Simple joints between stone blocks and between stone block arches with columns which are also composed of circle piles of stones (Sedayu, 2013). This ancient arch is also applied to columns and dome with a two-level which applied at the Cordoba mosque provides a high architectural aesthetic and structural stability (Figure 6). The application of this arches structure is also applied to the architecture of modern mosques, both on the dome and on the bonding of the columns. Figure 7 is a configuration and a regular grid of arches supporting each other to achieve the stability of the Cordoba Mosque.

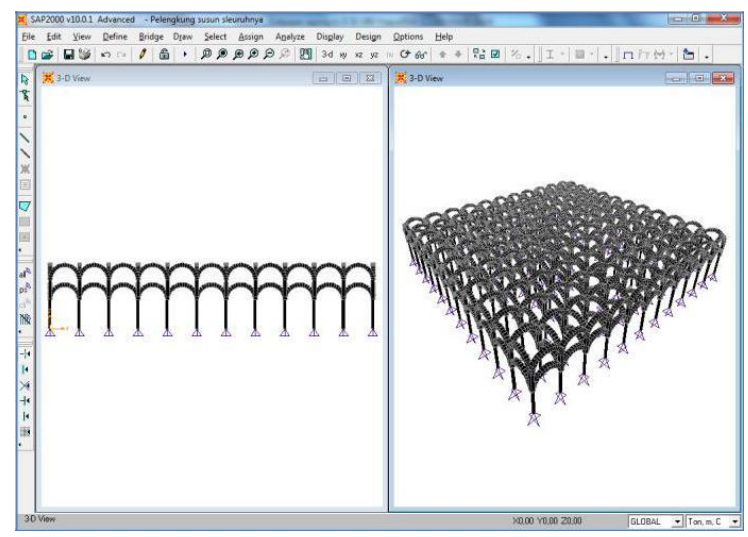

Figure 7. The arches structures that support each other.
The arches structures with simple stacks of stones or bricks have developed in almost all European buildings since the past. The beginning of arches technology developed since Roman period in the 2 nd century BC. Its use is motivated by the unavailability of reinforced concrete, so it needs pre-stressed structural elements on the openings of both doors and windows. Besides create the effect of prestressing (pre-stress) on rocks and bricks in simple arches, the shape of the curvature will provide a more interesting and dynamic aesthetic and architectural value. The large weight of a stone or brick makes the arches structure have a large gravitational load that strengthens the stability of the structure, until the position and location of the arches structure does not move. The results of structural analysis of the arches structure model design in Figure 7 obtain maximum deflection in the columns and arches. Deflection is one of damage indicators in structure. Deflection is a change in shape of the structural elements in the vertical and horizontal directions due to the loading on the beam or bar. The axis of a bar will be deflected from its position and location when the object is under the influence of the load that occurs. In other words, a bar which is loaded by transverse loading both point load and distributed load will be deflected (Sedayu, 2015).

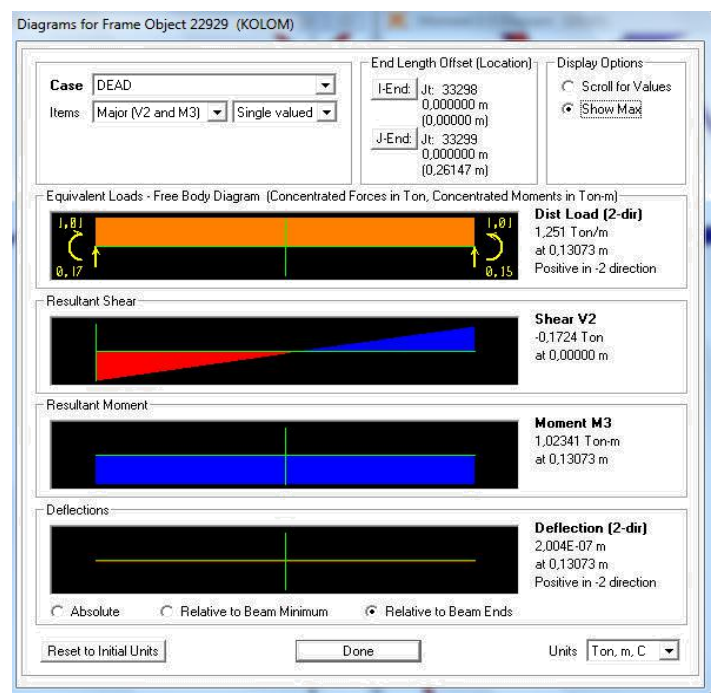

Figure 8. The results of the largest deflection analysis on the arches of the Cordoba Mosque.

A structural element has a maximum deflection capacity, with description each deflection may not exceed the maximum ultimate deflection. Figure 8 is the result of the analysis to know the deflection in the arches, with the biggest dflection equal to $2 \times 10^{-7} \mathrm{~m}$ almost in the middle of the arches span. This result is below of the maximum ultimate deflection equal to L / $240=3 / 240=0.0125 \mathrm{~m}$ (with $\mathrm{L}=$ length of the arche span). It can be concluded that the arch of the Cordoba Mosque is relatively stable and has a safety level of deflection with $2 \times 10^{-7} \mathrm{~m}<0.0125 \mathrm{~m}$. 


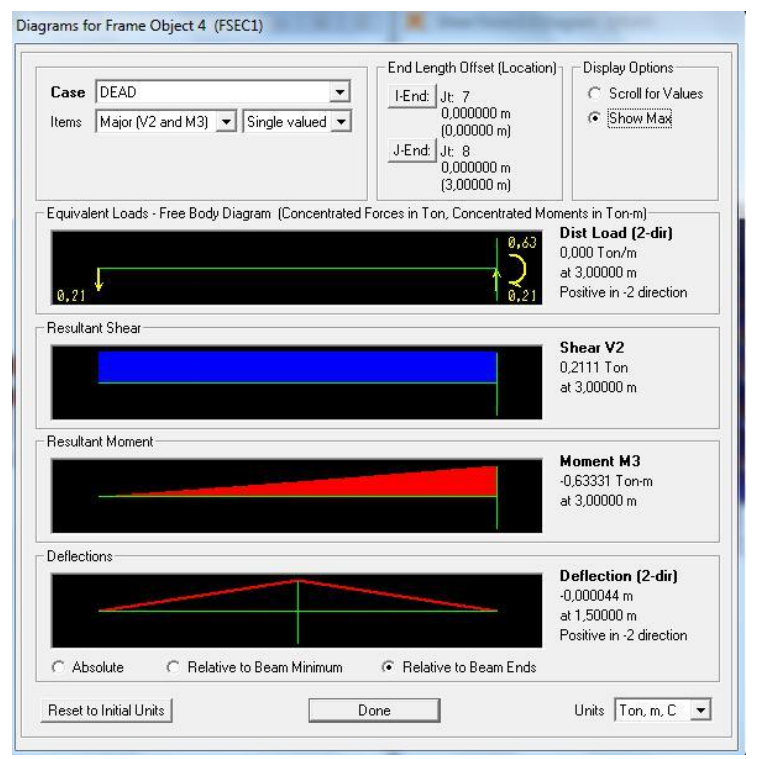

Figure 9. The results of the maximum analysis to column in the Cordoba Mosque.

The load supported by each arch is included in the analysis of SAP 2000 non-linear equalt to 1 ton $/ \mathrm{m}$. Figure 9 shows the results of the largest deflection analysis to column in the Cordoba Mosque with a deflection level equal to $4.4 \times 10^{-4} \mathrm{~m}$. This result is classified as stable and safe when compared to the provisions of the maximum ultimate deflection of $\mathrm{h} /$ $500=3 / 500=0.006 \mathrm{~m}$ (with $\mathrm{h}=$ column height) with $4.4 \times 10^{-4} \mathrm{~m}<0.006 \mathrm{~m}$.

\section{CONCLUSIONS}

The funicular structure at the Cordoba Mosque consists of a pair of stones stacked with a simple joint. Between one and the other funiculars provide strength each other. The funicular structure used is the arc type. The type of arches at the Cordoba mosque which are three hinge arches with the many hinges that jointed between arche stones. The Cordoba mosque in Spain that applies ancient arches with stone stacked. Simple stacks between stone blocks and between arch stone blocks with columns which are also composed of rounded stones. This ancient arch is also applied to the columns and domes with a two-level applied at the Cordoba mosque provide architectural aesthetics and high structural reliability. Besides giving the effect of prestressing (pre-stress) to the rocks and the bricks in simple arches, the shape of the curvature will provide a more interesting in dynamic aesthetic and architectural value. The large weight of stone or brick makes the arches structure have a large gravitational load that strengthens the stability of the structure, so the position and location of the arches structure does not move. A structural element has a maximum deflection capacity, where each deflection may not exceed the maximum ultimate deflection. The result of the deflection analysis in the largest arch with a deflection of $2 \times 10-7 \mathrm{~m}$ almost in the middle of the arch span. This result is below the maximum ultimate deflection of $\mathrm{L} / 240=$ $3 / 240=0.0125 \mathrm{~m}$ (with $\mathrm{L}=$ length of the arches span). It can be concluded that the arch of the Cordoba Mosque is relatively stable and has a safety level of deflection with $2 \times 10-7 \mathrm{~m}<0.0125 \mathrm{~m}$. The biggest deflection analysis in the the column of Cordoba Mosque with a large deflection of $4.4 \times 10-4 \mathrm{~m}$. This result is classified as stable and safe when compared to the maximum ultimate deflection of $\mathrm{h} / 500=3 / 500=$ $0.006 \mathrm{~m}$ (with $\mathrm{h}=$ column height) with $4.4 \times 10-4 \mathrm{~m}$ $<0.006 \mathrm{~m}$. In general, the construction of Cordoba's funiculars with arrangement of columns and arcs has a safe and stable level of deflection so that it does not cause significant damage.

\section{REFERENCES}

Sanjaya H. 2012. Traveling to find the cordoba mosques in andalusia. www.creativecommons.or.id

Pramono H. 2007. Design in Plate Construction and Reinforced Concrete Frame with SAP 2000. Yogyakarta: Andi

Arce I. 2006. Umayyad Arches, Vaults \& Domes: Merging and Recreation. Contributions to Early Islamic Construction History. Proceeding of the second international Congress on Construction History, Cambridge Vol 1 195-220

Fuentes P, Huerta S. 2010. Islamic domes of crossed-arches: Origin, geometry and structural behavior. Arch' 10. 6th International Conference on Arch

Bridges (Fuzhou, China, October 11-13, 2010) Fuzhou, China: College of Civil Engineering, Fuzhou University, 2010, pp. 346353.

Hildebrand T. 2012. Architectural Origins of the Mosque of Cordoba. Nebraska Anthropologist, Volume 27 University of Nebraskan-Lincoln's AnthroGroup

Sedayu A. 2013. Equilibrium analysis of truss structure by Cullmann, Henneberg, and SAP 2000 Methods. Proceedings of the 3rd National Seminar on Islamic Architecture. Maulana Malik Ibrahim State Islamic University of Malang

Sedayu A. 2017. Modeling in Simple Beam Structure with SAP 2000 and Autodesk RSA Professional. International Proceeding on Green Technology. http://proceeding-greentech.com

Sedayu A. 2018. The priority of maintaining the reliability of sustainable construction at the Ampel mosque Surabaya, MATEC Web of conferences (indexed by Scopus).

Sedayu A, Mangkoedihardjo S. 2018. Performance evaluation of housing contractor by applying the principles of environmentally friendly infrastructure, International Journal of Civil Engineering and Technology, Volume 9, Issue 4 April 2018, pp.1014-1022 ISSN Print : 0976-6308 and ISSN Online : 0976-6316, 2018.

Sedayu A. 2013. Engineering Mechanic : The determinate Static Structure Volume 2. Malang : UIN Maliki Press.

Sedayu A. 2015. Engineering Mechanic : The determinate Static Structure Volume 3. Malang : UIN Malik Press. 